\title{
Endoscopic hemostasis through gastrostomy
}

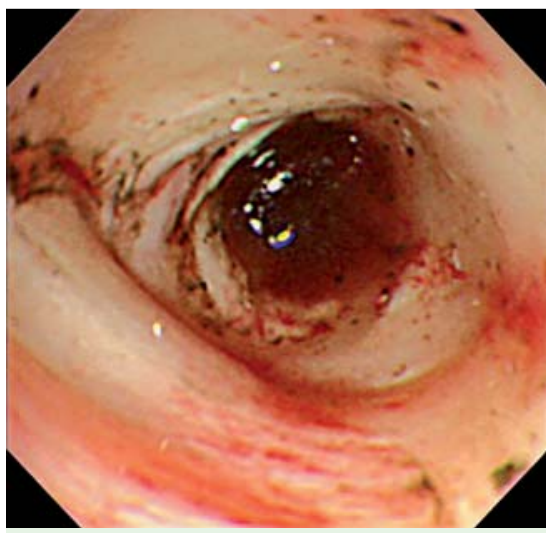

Fig. 1 The gastrointestinal scope (Olympus XP260N; Olympus Corp., Tokyo, Japan) could be passed without difficulty through the gastrostomy into the stomach.

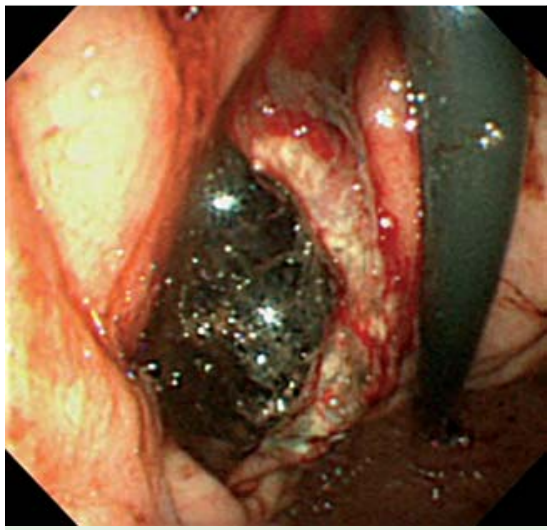

Fig. 2 Oozing of blood was observed from the lesion in the body of the stomach.

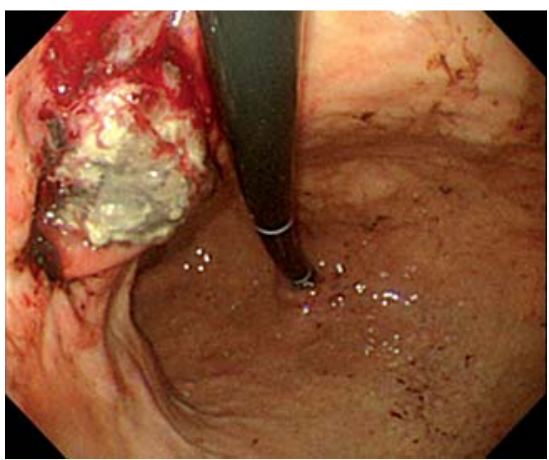

Fig. 3 Endoscopic hemostasis was achieved using argon plasma coagulation performed using the gastrointestinal Olympus Q260 scope (Olympus Corp., Tokyo, Japan) inserted via the gastrostomy tube.

A 60-year-old man suffering from esophageal cancer was admitted to our hospital due to tarry stools. He had difficulty with oral intake due to stricture caused by the

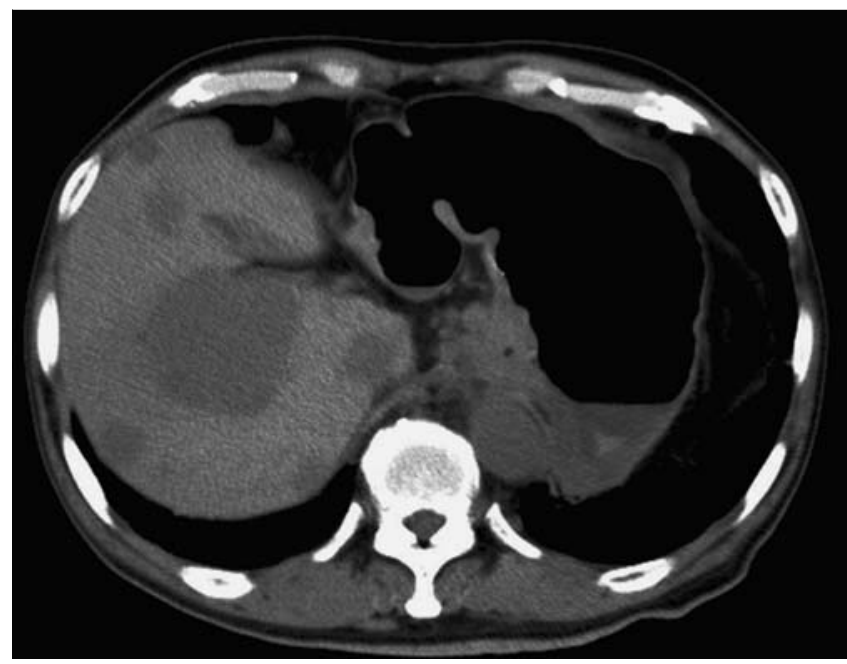

Fig. 4 Computed tomography of the abdomen revealed invasion of the stomach by a cancerous lymph node (No. 3).

esophageal cancer and received his nutrition via gastrostomy. Laboratory findings revealed severe anemia, and gastrointestinal bleeding was therefore suspected. The stricture caused by the esophageal cancer made it impossible to pass the gastrointestinal endoscope. As a last resort, therefore, endoscopy via the gastrostomy was attempted in order to identify and treat the source of bleeding. We were able to pass the gastrointestinal scope (Olympus XP260N; Olympus Corp., Tokyo, Japan), via the gastrostomy port into the stomach ( $\bullet$ Fig. 1$)$.

Oozing of blood was observed from a lesion in the body of the stomach ( $\bullet$ Fig. 2 ). Endoscopic hemostasis was achieved using argon plasma coagulation ( $\mathbf{F i g}$. 3) after changing the scope to an Olympus Q260.

Computed tomographic examination revealed that the bleeding was caused by invasion of the stomach by a cancerous lymph node (No. 3) ( Fig. 4).

Since it was first described in 1980, percutaneous endoscopic gastrostomy tube placement has been widely used for longterm nutritional support in patients with severe neurological impairment [1]. However, to date, endoscopic hemostasis through a gastrostomy has scarcely been reported. In our present case, there were no complications associated with hemostasis achieved endoscopically via gastrostomy. It is therefore suggested that in patients with a gastrostomy, the gastrostomy tube may serve as a valid alternative approach for endoscopy.
Competing interests: None

Endoscopy_UCTN_Code_TTT_1AO_2AD

T. Uchiyama ${ }^{1}$, A. Goto ${ }^{2}$, E. Sakai ${ }^{1}$, Y. Sekino ${ }^{1}$, H. lida ${ }^{1}$, H. Endo ${ }^{1}$, K. Hosono $^{1}$, Y. Sakamoto ${ }^{1}$, T. Koide ${ }^{1}$, H. Takahashi $^{1}$, M. Yoneda ${ }^{1}$, C. Tokoro ${ }^{1}$, Y. Abe ${ }^{1}$, T. Shimamura ${ }^{1}$, N. Kobayashi ${ }^{1}$, K. Kubota $^{1}$, S. Maeda', A. Nakajima ${ }^{1}$, Y. Ichikawa $^{2}$, M. Inamori ${ }^{1}$

1 Gastroenterology Division, Yokohama City University School of Medicine, Yokohama, Japan

2 Division of Oncology, Yokohama City University School of Medicine,

Yokohama, Japan

\section{References}

1 Gauderer MW, Ponsky JL, Izant RJ Jr. Gastrostomy without laparotomy: a percutaneous endoscopic technique. J Pediatr Surg 1980; 15: $872-875$

\section{Bibliography}

DOI $10.1055 / \mathrm{s}-0030-1255772$

Endoscopy 2010; 42: E270

(c) Georg Thieme Verlag KG Stuttgart · New York ISSN 0013-726X

\section{Corresponding author}

\section{Inamori, MD, PhD}

Gastroenterology Division

Yokohama City University School of Medicine 3-9 Fukuura

Kanazawa-ku

Yokohama, 236-0004

Japan

Fax: +81-45-7843546

inamorim@med.yokohama-cu.ac.jp 